\title{
COBRE E ZINCO NO MATERIAL PERCOLADO E NO SOLO COM A APLICAÇÃO DE ÁGUA RESIDUÁRIA DE SUINOCULTURA EM SOLO CULTIVADO COM SOJA ${ }^{1}$
}

\author{
ADRIANA SMANHOTTO ${ }^{2}$, ANTÔNIO DE P. SOUSA ${ }^{3}$, SILVIO C. SAMPAIO ${ }^{4}$, \\ LÚCIA H. P. NÓBREGA ${ }^{5}$, MARITANE PRIOR ${ }^{6}$
}

\begin{abstract}
RESUMO: O objetivo deste trabalho foi avaliar possíveis efeitos da aplicação de taxas de água residuária de suinocultura (ARS), quanto às concentrações de cobre e zinco, tanto no solo quanto na água percolada de lisímetros de drenagem, durante o ciclo da cultura da soja. O experimento foi conduzido em ambiente protegido, onde havia 24 lisímetros de drenagem. Semeou-se soja cultivar CD 202, e foram aplicadas ARS nas seguintes dosagens: 0; 100; 200 e $300 \mathrm{~m}^{3} \mathrm{ha}^{-1}$ no ciclo, combinadas com duas adubações na semeadura (com e sem adição da adubação recomendada na semeadura), em três repetições por tratamento. Foram feitas seis coletas do material percolado durante o ciclo da cultura e realizadas determinações de cobre e zinco. No solo, foram feitas três coletas em cada parcela experimental, para a determinação do $\mathrm{pH}$, da matéria orgânica, da capacidade de troca catiônica, do cobre e do zinco. O delineamento foi em blocos casualizados, num esquema fatorial de $4 \times 2$. Observou-se que o cobre no solo não apresentou diferenças significativas com a aplicação de ARS e adubação, enquanto as concentrações de zinco no solo foram influenciadas pelas taxas aplicadas de ARS. As transferências de cobre e de zinco por percolação foram pouco expressivas.
\end{abstract}

PALAVRAS-CHAVE: reúso de água, lixiviação, lisímetros.

\section{COPPER AND ZINC IN THE LIXIVIATED MATERIAL AND IN THE SOIL APPLICATION OF SWINE WASTEWATER ON SOIL CULTIVATED WITH SOYBEAN}

\begin{abstract}
The objective of this paper is to evaluate the possible effects of applying different rates of swine wastewater (ARS), when it comes to the concentration of copper and zinc and in the percolated water of drainage lysimeters on the soil cultivated with soybeans. The experiment was conducted in a protected environment containing 24 drainage lysimeters. Cultivar CD 202 was sowed and swine wastewater was applied in the following dosages: 0, 100, 200, and $300 \mathrm{~m}^{3} \mathrm{ha}^{-1}$ during the cycle, combined with two fertilizing at sewing (with and without added fertilizing recommended at sewing), in three repetitions per treatment. It was accomplished six collections of percolated material during the crop cycle and it was determinate both copper and zinc. In soil, three collections were accomplished in each experimental plot to determine the $\mathrm{pH}$, organic matter, cationic exchange capacity, copper and zinc. The experiment delimitation was carried out in random blocks in a 4 × 2 factorial scheme. It was observed that copper did not present differences in the application of ARS and fertilizer, while the concentration of zinc on the soil was influenced by rates of ARS Copper and zinc transfer per lixiviation was not meaningful.
\end{abstract}

KEYWORDS: water reuse, lixiviation, lysimeters.

\footnotetext{
${ }^{1}$ Extraído da Tese de Doutorado do primeiro autor.

${ }^{2}$ Eng ${ }^{a}$ Agrícola, Professora, Centro de Ciências, Tecnologia e Produção, PUC, Toledo - PR, Fone: (0XX45) 3277.8600, adrianasmanhotto@hotmail.com

${ }^{3}$ Eng $^{\mathrm{o}}$ Agrônomo, Prof. Assistente, Departamento de Engenharia Rural, FCA/UNESP, Botucatu - SP.

${ }^{4}$ Eng $^{\mathrm{O}}$ Agrícola, Prof. Adjunto, Centro de Ciências Exatas e Tecnológicas, UNIOESTE, Cascavel - PR.

${ }^{5}$ Eng $^{\mathrm{a}}$ Agrônoma, Prof. Adjunto, Centro de Ciências Exatas e Tecnológicas, UNIOESTE, Cascavel - PR.

${ }^{6}$ Eng $^{\mathrm{a}}$ Agrícola, Prof. Adjunto, Centro de Ciências Agrárias, UNIOESTE, Cascavel - PR.

Recebido pelo Conselho Editorial em: 15-12-2008

Aprovado pelo Conselho Editorial em: 12-12-2009
} 


\section{INTRODUÇÃO}

A atividade suinícola no Brasil tem importância econômica e social por gerar divisas, emprego e renda, constituindo, dentro do sistema de produção animal, alternativa para viabilizar pequenas propriedades rurais. A região oeste do Paraná, em especial, detém o maior plantel de suínos do Estado. Por outro lado, a suinocultura acarreta problemas ambientais decorrentes da destinação inadequada dos dejetos gerados nas propriedades, sendo que o problema crucial na criação de suínos reside no apreciável volume de dejetos produzido por animal e na sustentabilidade ambiental da sua produção.

A reciclagem dessas águas residuárias de suínos, como fertilizante orgânico, tem sido feita, uma vez que possui uma série de elementos químicos prontamente disponíveis, ou que, depois de adicionada ao solo, promove mineralização dos elementos que poderão ser absorvidos pelas plantas da mesma forma que os dos fertilizantes minerais. Entretanto, ao contrário dos fertilizantes minerais, a água residuária de suinocultura possui composição química muito variável, principalmente em função da alimentação e do manejo da água empregada nos criatórios (BASSO et al., 2005) e que se encontra em quantidades desproporcionais em relação à capacidade de extração das plantas. Com isso, a disposição contínua de águas residuárias de suinocultura ao longo dos anos, nas mesmas áreas, poderá causar sérios problemas com contaminação de águas subsuperficias e rios por meio do nitrato e do fósforo, por exemplo (CERETTA et al., 2005; BASSO et al., 2005).

Outro problema é a possibilidade de contaminação do solo e da água devido à alta concentração de metais pesados, como $\mathrm{Zn}$ e $\mathrm{Cu}$, que os dejetos líquidos de suínos possuem (HSU \& LO, 2000; GRÄBER et al., 2005; MATTIAS, 2006). A presença de elementos como Cu e Zn em alta concentração nos dejetos é consequência da adição de quantidades excessivas de $\mathrm{Cu}$ e $\mathrm{Zn}$ nas rações dos suínos com o objetivo de prevenir doenças, melhorar a digestão e promover o crescimento. Entretanto, essa suplementação com fontes de $\mathrm{Cu}$ e $\mathrm{Zn}$, em certo grau, às vezes excede grandemente o requerimento fisiológico dos suínos (JONDREVILLE et al., 2003). Sendo assim, essa é uma das principais causas da alta concentração de $\mathrm{Cu}$ e $\mathrm{Zn}$ nos dejetos de suínos. Esse fato, associado às aplicações sucessivas de dejeto, tende a causar acúmulos de $\mathrm{Cu}$ e $\mathrm{Zn}$ no solo, tornando os dejetos uma fonte poluidora com alto potencial de contaminação ambiental (GIROTTO, 2007).

A aplicação de água residuária de suinocultura na superfície do solo e a avaliação da transferência de elementos, como fósforo e nitrogênio via escoamento superficial e percolação para espelhos de água superficial e águas subsuperficiais, têm sido temas de inúmeros trabalhos (BASSO et al., 2005; CERETTA et al., 2005). Entretanto, dados de transferência de metais pesados por percolação no solo são escassos. Dessa forma, estudar taxas de aplicação de dejetos suínos no solo, para verificar as mais condizentes com a reposição dos nutrientes retirados pela planta, sua contribuição para a conservação e a fertilidade dos solos agrícolas e potencial poluidor, considerando o tipo de solo, as características da água residuária de suinocultura, as condições climáticas da região e a cultura cultivada, assumem fundamental importância (DAL BOSCO, 2007).

Nesse contexto, o objetivo deste trabalho foi avaliar possíveis efeitos da aplicação de taxas de água residuária de suinocultura, quanto às concentrações de cobre e zinco, tanto no solo quanto na água percolada de lisímetros de drenagem, durante o ciclo da cultura da soja.

\section{MATERIAL E MÉTODOS}

O experimento foi desenvolvido no Núcleo Experimental de Engenharia Agrícola - NEEA, da Universidade Estadual do Oeste do Paraná - UNIOESTE, Câmpus de Cascavel. A área está localizada geograficamente pelas coordenadas $24^{\circ} 48^{\prime}$ de latitude sul e $53^{\circ} 26^{\prime}$ de longitude oeste, com altitude de $760 \mathrm{~m}$. O solo da área experimental foi classificado como Latossolo Vermelho distroférrico típico. Na Tabela 1, é apresentada a caracterização do solo antes da implantação do experimento. 
TABELA 1. Caracterização química do solo nos lisímetros antes da instalação do experimento. Chemical characterization of soil in the lysimeters before installation of the experiment.

\begin{tabular}{cccccc}
\hline Profundidade & $\begin{array}{c}\mathrm{pH} \\
\mathrm{CaCl}_{2}\end{array}$ & $\begin{array}{c}\text { M.O. } \\
\mathrm{g} \mathrm{dm}^{-3}\end{array}$ & $\begin{array}{c}\mathrm{CTC} \\
\mathrm{mmol}_{\mathrm{c}} \mathrm{dm}^{-3}\end{array}$ & \multicolumn{2}{c}{$\mathrm{Cu}$} \\
\hline $0-0,60$ & 6,6 & 24 & 210 & 5,2 & $\mathrm{mg} \mathrm{dm}^{-3}$ \\
\hline
\end{tabular}

$\mathrm{Na}$ área de implantação, havia 24 lisímetros de drenagem, em ambiente protegido de $96 \mathrm{~m}^{2}$ de área. Cada lisímetro de drenagem apresentava volume de $1 \mathrm{~m}^{3}$ e área de $1,60 \mathrm{~m}^{2}$, compreendendo uma parcela experimental.

Semeou-se soja, cultivar CD 202, da Coodetec - Cooperativa Central de Pesquisa Agrícola com ciclo precoce de 118 dias. A semeadura foi manual e ocorreu no dia 2 de dezembro de 2006, em cada um dos lisímetros, na densidade de 15 sementes por metro linear. A adubação na semeadura foi de $250 \mathrm{~kg} \mathrm{ha}^{-1}$ na fórmula 0-20-20, de acordo com a análise do solo apresentada na Tabela 1.

Instalou-se o sistema de irrigação por gotejamento, e as linhas laterais foram dispostas ao longo das linhas da cultura implantada. Aos quatorze dias após a semeadura (14 DAS), realizou-se a primeira irrigação, a fim de não causar estresse hídrico às plantas. A partir dos 44 DAS, semanalmente, fez-se a irrigação, num total de sete irrigações na cultura da soja: 14 DAS, 44 DAS, 58 DAS, 72 DAS, 86 DAS, 100 DAS e 114 DAS. A quantidade de água aplicada via irrigação foi baseada de acordo com a precipitação média provável para a região, segundo LONGO et al. (2006), num total de $72 ; 79 ; 112 ; 91 ; 81 ; 65$ e 76 mm, respectivamente, em cada irrigação. A ARS utilizada foi coletada numa propriedade rural que contém um Biossistema Integrado, ou seja, é tratada em um biodigestor seguido de um tanque de sedimentação e lagoa de estabilização, sendo na saída desta o ponto de coleta. A caracterização média da ARS é apresentada na Tabela 2.

TABELA 2. Caracterização média da ARS utilizada durante o experimento. Mean characterization ARS used during the experiment.

\begin{tabular}{cccccccc}
\hline \multicolumn{7}{c}{ Parâmetros } \\
\hline $\mathrm{pH}$ & DBO & DQO & Nitrogênio Total & Nitrato & Nitrito & Cobre & Zinco \\
\hline & & \multicolumn{7}{c}{$\mathrm{mg} \mathrm{L}^{-1}$} & & & \\
\hline 7,73 & 671,04 & $1.444,07$ & 1,52 & 1,52 & 2,03 & 0,20 & 1,17 \\
\hline
\end{tabular}

Análise realizada no Laboratório Solanálise de acordo com a metodologia de APHA, AWWA \& WEF (1998).

O delineamento experimental foi em blocos casualizados, em esquema fatorial (4x2), com três repetições. Os tratamentos aplicados às parcelas consistiram em quatro taxas de aplicação de ARS $\left(0 ; 100 ; 200\right.$, e $300 \mathrm{~m}^{3} \mathrm{ha}^{-1}$ no ciclo) e dois níveis de adubação (com ou sem adubação química na semeadura). As taxas de ARS foram divididas em seis aplicações. Ressalta-se que todos os lisímetros receberam a mesma quantidade em volume de água, de forma a completar a aplicação com água residuária. Durante a condução do experimento, foram coletadas, de cada parcela amostras do percolado em seis períodos, sempre após a realização da irrigação. As amostras foram armazenadas em frascos plásticos de $1.000 \mathrm{~mL}$ e refrigeradas em caixa de isopor com gelo, durante o deslocamento ao laboratório, onde se determinaram o pH, cobre e zinco, de acordo com APHA, AWWA \& WEF (1998).

Foram coletadas amostras de solo em cada lisímetro, na profundidade de 0-60, abrangendo todo o perfil da parcela experimental. As coletas foram realizadas em três momentos: antes da semeadura da cultura da soja, aos 59 DAS e ao final do ciclo da soja (118 DAS). Fizeram-se a determinação de $\mathrm{pH}$, matéria orgânica, capacidade de troca catiônica, cobre e zinco, segundo metodologias descritas por RAIJ et al. (2001). Fez-se a análise de variância, a 5\% de probabilidade, em cada período de coleta isoladamente, tanto para o percolado quanto para o solo. Utilizou-se da 
mesma análise estatística para os resultados do solo antes da semeadura, uma vez que, na área, haviam sido aplicadas taxas semelhantes de ARS.

\section{RESULTADOS E DISCUSSÃO}

$\mathrm{Na}$ Tabela 3, é apresentado o resumo da análise de variância dos valores médios de $\mathrm{pH}$ do extrato aquoso do solo, da matéria orgânica e da capacidade de troca de cátions (CTC), em função dos tratamentos com ARS e adubação nos períodos de coleta.

TABELA 3. Resumo da análise de variância para a obtenção dos valores de $\mathrm{F}$ do $\mathrm{pH}\left(\mathrm{CaCl}_{2}\right)$ do extrato aquoso do solo, matéria orgânica $\left(\mathrm{g} \mathrm{dm}^{-3}\right)$ e CTC $\left(\mathrm{mmol}_{\mathrm{c}} \mathrm{dm}^{-3}\right)$ sob tratamento com as taxas de aplicação da água residuária de suinocultura e adubação, nos períodos de coleta. Summary of variance analysis to obtain the $\mathbf{F}$ values of the $\mathbf{p H}\left(\mathrm{CaCl}_{2}\right)$ of aqueous extract of soil, organic matter $\left(\mathrm{g} \mathrm{dm}^{-3}\right)$ and CTC $\left(\mathrm{mmol}_{\mathrm{c}} \mathrm{dm}^{-3}\right)$ under treatment with the application rates of swine wastewater and fertilizing in the collection periods.

\begin{tabular}{|c|c|c|c|c|c|c|c|c|c|}
\hline \multirow{3}{*}{$\begin{array}{l}\text { Fonte de } \\
\text { Variaçãao }\end{array}$} & \multicolumn{3}{|c|}{$\mathrm{pH}$ do solo } & \multicolumn{3}{|c|}{ Matéria Orgânica } & \multicolumn{3}{|c|}{ CTC } \\
\hline & \multicolumn{9}{|c|}{$\mathrm{F}$} \\
\hline & $0 \mathrm{DAS}$ & $59 \mathrm{DAS}$ & $118 \mathrm{DAS}$ & 0 DAS & 59 DAS & 118 DAS & 0 DAS & 59 DAS & $118 \mathrm{DAS}$ \\
\hline ARS & $2,33^{\mathrm{ns}}$ & $9,94^{*}$ & $11,10^{*}$ & $0,48^{\text {ns }}$ & $7,99^{*}$ & $7,55^{*}$ & $2,07^{\mathrm{nS}}$ & $6,58^{*}$ & $3,74^{*}$ \\
\hline $\mathrm{AD}$ & $0,50^{\mathrm{ns}}$ & $2,69^{\mathrm{ns}}$ & $0,01^{\text {ns }}$ & $2,50^{\mathrm{ns}}$ & $1,81^{\mathrm{ns}}$ & $0,17^{\mathrm{ns}}$ & $0,11^{\mathrm{ns}}$ & $2,12^{\mathrm{ns}}$ & $0,16^{\mathrm{ns}}$ \\
\hline ARS x AD & $2,82^{\mathrm{ns}}$ & $1,09^{\mathrm{ns}}$ & $0,06^{\mathrm{ns}}$ & $0,98^{\mathrm{ns}}$ & $1,10^{\mathrm{ns}}$ & $0,83^{\mathrm{ns}}$ & $1,27^{\mathrm{ns}}$ & $0,64^{\mathrm{ns}}$ & $1,81^{\mathrm{ns}}$ \\
\hline Bloco & $0,26^{\mathrm{ns}}$ & $0,47^{\mathrm{ns}}$ & $1,77^{\mathrm{ns}}$ & $6,79^{\mathrm{ns}}$ & $0,20^{\mathrm{ns}}$ & $2,73^{\mathrm{ns}}$ & $0,59^{\mathrm{ns}}$ & $0,26^{\mathrm{ns}}$ & $0,26^{\mathrm{ns}}$ \\
\hline C.V. (\%) & 2,19 & 2,91 & 2,83 & 10,95 & 7,05 & 8,82 & 9,30 & 13,11 & 18,36 \\
\hline Média geral & 6,57 & 6,41 & 6,58 & 23,58 & 27,96 & 28,29 & 139 & 148 & 154 \\
\hline
\end{tabular}

Observa-se que o valor de F para $\mathrm{pH}$, matéria orgânica e CTC foi significativo para as taxas de aplicação de ARS nos períodos de 59 e 118 DAS. Os coeficientes de variação foram classificados como baixos, uma vez que foram inferiores a 10\%, representando dados homogêneos e médios, indicando homogeneidade média dos dados, já que se apresentaram no intervalo de 10 a 20\% (PIMENTEL GOMES, 2000).

$\mathrm{Na}$ Tabela 4, é apresentado o resultado do teste de comparação de médias dos valores de $\mathrm{pH}$ no extrato aquoso do solo, matéria orgânica e capacidade de troca de cátions (CTC), de acordo com as taxas de aplicação de ARS, nos períodos de 59 e 118 DAS.

TABELA 4. Médias do pH $\left(\mathrm{CaCl}_{2}\right)$, matéria orgânica $\left(\mathrm{g} \mathrm{dm}^{-3}\right)$ e $\mathrm{CTC}\left(\mathrm{mmol}_{\mathrm{c}} \mathrm{dm}^{-3}\right)$ do solo, em função dos tratamentos com água residuária de suinocultura, nos períodos de 59 e 118 dias após a semeadura. Means of $\mathbf{p H}\left(\mathrm{CaCl}_{2}\right)$, organic matter $\left(\mathrm{g} \mathrm{dm}^{-3}\right)$ and CTC $\left(\mathrm{mmol}_{\mathrm{c}} \mathrm{dm}^{-3}\right)$ of soil, in function of the treatment of swine wastewater in the periods of 59 and 118 days after sewing.

\begin{tabular}{ccccccc}
\hline \multirow{2}{*}{ Taxas $\left(\mathrm{m}^{3} \mathrm{ha}^{-1}\right)$} & \multicolumn{2}{c}{$\mathrm{pH}$ do Solo } & \multicolumn{2}{c}{ Matéria Orgânica } & \multicolumn{2}{c}{$\mathrm{CTC}$} \\
\cline { 2 - 7 } & $59 \mathrm{DAS}$ & $118 \mathrm{DAS}$ & $59 \mathrm{DAS}$ & $118 \mathrm{DAS}$ & $59 \mathrm{DAS}$ & $118 \mathrm{DAS}$ \\
\hline 0 & $6,18 \mathrm{~A}$ & $6,22 \mathrm{~A}$ & $25,50 \mathrm{~A}$ & $24,67 \mathrm{~A}$ & $122 \mathrm{~A}$ & $128 \mathrm{~A}$ \\
100 & $6,23 \mathrm{~A}$ & $6,58 \mathrm{~B}$ & $27,00 \mathrm{~A}$ & $28,50 \mathrm{AB}$ & $144 \mathrm{AB}$ & $149 \mathrm{AB}$ \\
200 & $6,57 \mathrm{~B}$ & $6,72 \mathrm{~B}$ & $28,50 \mathrm{AB}$ & $28,50 \mathrm{AB}$ & $153 \mathrm{AB}$ & $159 \mathrm{AB}$ \\
300 & $6,67 \mathrm{~B}$ & $6,78 \mathrm{~B}$ & $30,83 \mathrm{~B}$ & $31,50 \mathrm{~B}$ & $171 \mathrm{~B}$ & $181 \mathrm{~B}$ \\
\hline
\end{tabular}

Letras maiúsculas iguais na coluna não diferem entre si, de acordo com o teste de Tukey, a 5\% de significância. DAS - dias após a semeadura.

Observa-se, pela Tabela 4, que os valores médios do $\mathrm{pH}$ do extrato aquoso do solo, aos 59 DAS, foi maior para a maior taxa de ARS $\left(300 \mathrm{~m}^{3} \mathrm{ha}^{-1}\right)$, o qual diferiu significativamente da 
testemunha $\left(0 \mathrm{~m}^{3} \mathrm{ha}^{-1}\right)$ e da taxa de $100 \mathrm{~m}^{3} \mathrm{ha}^{-1}$. Verifica-se, aos $118 \mathrm{DAS}$, que o menor valor médio do $\mathrm{pH}$ do extrato aquoso do solo foi verificado para a testemunha $\left(0 \mathrm{~m}^{3} \mathrm{ha}^{1}\right)$, a qual diferiu a 5\% de significância das demais taxas de aplicação de ARS. Nesse sentido, PEREIRA (2006) também observou variação do $\mathrm{pH}$ do solo nos tratamentos em que foi adicionado água residuária de suinocultura, encontrando valores que variaram de 4,2 a 5,4. Segundo o autor, atribuiu-se tal fato ao elevado valor do $\mathrm{pH}$ da ARS aplicada no solo $(7,0$ a 8,1), o que pode estar associado ao comportamento do $\mathrm{pH}$ no presente estudo, uma vez que a ARS utilizada apresentou pH de 7,4 a 8,3. ASSMANN et al. (2006) constataram, em curto período de tempo, influência das doses de esterco líquido suíno sobre o $\mathrm{pH}$ do solo. A aplicação do esterco líquido suíno, segundo os autores, aumentou o $\mathrm{pH}$ de 4,52 para 4,79, com as doses de 0 e $80 \mathrm{~m}^{3} \mathrm{ha}^{-1}$, respectivamente. Entretanto, CERETTA et al. (2003) verificaram que o pH do solo praticamente não foi alterado com a aplicação de 20 a $40 \mathrm{~m}^{3} \mathrm{ha}^{-1}$ de ARS em pastagem.

Com relação à matéria orgânica, nota-se, na Tabela 4, que o teor variou em função da aplicação das taxas de ARS, indicando que a matéria orgânica presente no dejeto suíno proporcionou valores maiores. Observa-se que aos 59 DAS, o menor teor de matéria orgânica foi obtido para a testemunha $\left(0 \mathrm{~m}^{3} \mathrm{ha}^{-1}\right)$ e que diferiu ao nível de $5 \%$ da taxa de $300 \mathrm{~m}^{3} \mathrm{ha}^{-1}$, a qual foi semelhante apenas à taxa de $200 \mathrm{~m}^{3} \mathrm{ha}^{-1}$. No período de $118 \mathrm{DAS}$, nota-se também que o tratamento que não recebeu ARS obteve o menor teor de matéria orgânica, bem como a maior taxa de $300 \mathrm{~m}^{3} \mathrm{ha}^{-1}$, o maior teor, que foram diferentes ao nível de $5 \%$ de significância.

Comparando-se os valores de $\mathrm{pH}$ com o teor de matéria orgânica no solo, verifica-se que, com o aumento da matéria orgânica, houve aumento do $\mathrm{pH}$ no solo, o que também foi observado por HUE \& LICUDINE (1999) com aplicação de esterco de aves e lodo de esgoto no solo. Os autores atribuíram esse efeito à presença de compostos orgânicos, que aumentam significativamente no solo com a adição de grande quantidade de carbono. No entanto, DAL BOSCO (2007) não verificou aumento no teor de matéria orgânica do solo com a aplicação de ARS, fato que, segundo SCHERER et al. (1984), citado por BERTOL (2005), pode estar associado à baixa percentagem de matéria seca presente no dejeto, afetando pouco o teor de carbono no solo, uma vez que grande parte deste é perdido sob a forma de $\mathrm{CO}_{2}$.

ASMANN et al. (2006) não observaram aumento no teor de matéria orgânica com a aplicação de dejetos líquido de suínos, pois, segundo os autores, devem ser consideradas características intrínsecas do esterco utilizado, em que a qualidade dos compostos orgânicos pode determinar maior ou menor acúmulo de matéria orgânica no solo. Os compostos orgânicos presentes no esterco líquido de suínos são de fácil mineralização, oxidando em poucos dias ou semanas, favorecidos pela maior atividade microbiana decorrente do esterco aplicado. Ressalta-se que o aumento verificado no teor de matéria orgânica do solo pode estar associado a um efeito residual da ARS aplicada na área.

Verifica-se ainda, na Tabela 4, que a maior CTC foi verificada para a maior taxa de ARS nos dois períodos avaliados, a qual foi diferente, significativamente, do tratamento sem ARS e semelhante aos demais. Observa-se que houve incremento da matéria orgânica e, consequentemente, da CTC no solo, o que pode estar aliado à DBO presente na ARS (671,04 $\mathrm{mg} \mathrm{L}^{-1}$ ), pois, de acordo com SPERLING (1997), o lançamento de ARS no solo, com elevada carga de DBO, origina aumento da matéria orgânica, fato que também pode estar atrelado ao efeito residual da ARS na área experimental. QUEIROZ et al. (2004) aplicaram ARS em área com pastagem e também verificaram aumento da CTC em relação à testemunha que não recebeu ARS.

Na Tabela 5, é apresentado o resumo da análise de variância da concentração de cobre e de zinco no solo, em função dos tratamentos com ARS e adubação nos períodos de coleta. 
TABELA 5. Resumo da análise de variância para a obtenção dos valores de $\mathrm{F}$ da concentração de cobre e de zinco no solo $\left(\mathrm{mg} \mathrm{dm}^{-3}\right)$, considerando as taxas de aplicação da água residuária de suinocultura e adubação nos períodos de coleta. Summary of variance analysis to obtain the $F$ values of the concentration of copper and zinc on soil ( $\mathrm{mg}$ $\mathrm{dm}^{-3}$ ) considering the application rates of swine wastewater and fertilizing in the collection periods.

\begin{tabular}{lccrrrr}
\hline \multirow{2}{*}{ Fonte de Variação Cobre } & \multicolumn{3}{c}{ Zinco } \\
\cline { 2 - 6 } & \multicolumn{3}{c}{ F } & \multicolumn{3}{c}{} \\
\cline { 2 - 6 } & 0 DAS & 59 DAS & 118 DAS & 0 DAS & 59 DAS & 118 DAS \\
\hline ARS & $0,03^{\mathrm{ns}}$ & $0,15^{\mathrm{ns}}$ & $0,38^{\mathrm{ns}}$ & $0,78^{\mathrm{ns}}$ & $16,31^{*}$ & $11,28^{*}$ \\
$\mathrm{AD}$ & $0,68^{\mathrm{ns}}$ & $1,10^{\mathrm{ns}}$ & $1,30^{\mathrm{ns}}$ & $0,81^{\mathrm{ns}}$ & $0,38^{\mathrm{ns}}$ & $1,07^{\mathrm{ns}}$ \\
$\mathrm{ARS} \mathrm{x} \mathrm{AD}$ & $2,23^{\mathrm{ns}}$ & $0,55^{\mathrm{ns}}$ & $0,61^{\mathrm{ns}}$ & $2,52^{\mathrm{ns}}$ & $4,55^{\mathrm{ns}}$ & $3,02^{\mathrm{ns}}$ \\
Bloco & $5,96^{\mathrm{ns}}$ & $0,04^{\mathrm{ns}}$ & $0,14^{\mathrm{ns}}$ & $2,32^{\mathrm{ns}}$ & $0,69^{\mathrm{ns}}$ & $0,34^{\mathrm{ns}}$ \\
\hline C.V. (\%) & 18,08 & 22,56 & 16,64 & 18,78 & 19,80 & 24,12 \\
Média geral & 5,18 & 4,65 & 3,97 & 0,50 & 1,39 & 1,45 \\
\hline "indica que o valor de F é significativo, e "ns", que o valor de F não é significativo, a 5\% de significância. C.V. - coeficiente de \\
variação; DP - desvio-padrão; DAS - dias após a semeadura; AD - adubação. Utilizou-se a transformação $\sqrt{x}$.
\end{tabular}

Na Tabela 5, observa-se que o valor de $\mathrm{F}$ para o cobre não foi significativo para nenhum dos fatores avaliados nos três períodos. Isto implica que a concentração do cobre no solo não variou em função da adição da ARS e da adubação. Entretanto, para o zinco, os valores de $\mathrm{F}$ foram significativos para as taxas de ARS nos períodos de 59 e 118 DAS. Os coeficientes de variação foram classificados como médios (10 a 20\%), representando dados com homogeneidade média e alta maiores que 30\%, indicando dados com pouca homogeneidade (20 a 30\%) (PIMENTEL GOMES, 2000).

Embora as médias de cobre não tenham apresentado diferenças significativas, observa-se, na Tabela 5, por meio da média geral, que as concentrações de cobre diminuíram durante o desenvolvimento da cultura. Durante o desenvolvimento da cultura da soja, verifica-se que as concentrações de cobre diminuíram. No entanto, nota-se que, mesmo antes da semeadura e no decorrer do estudo, os teores de cobre no solo foram considerados como altos, segundo RAIJ et al. (2001), uma vez que foram maiores que $0,8 \mathrm{mg} \mathrm{dm}^{-3}$.

De acordo com MALAVOLTA et al. (2002), o total de cobre extraído e exportado pela soja, para cada tonelada, é de $26 \mathrm{~g}$, justificando o comportamento apresentado pelo cobre devido à remoção por parte da cultura. Os resultados observados no estudo corroboram QUEIROZ et al. (2004), que verificaram que o cobre, diferentemente do encontrado para outros nutrientes, teve sua concentração diminuída em ambos os tratamentos, indicando que esse mineral, além de ser em parte extraído pela cultura, tornou-se menos disponível em razão da complexação pela matéria orgânica do solo que era adicionada com a ARS, tornando-se, dessa forma, não extraível com extratores fracos. MATOS et al. (1997) também não verificaram aumento nas concentrações de $\mathrm{Cu}$ e de $\mathrm{Zn}$ trocáveis no perfil do solo submetido à aplicação de esterco líquido de suínos, nas doses de 0; 50; 100; 150 e $200 \mathrm{~m}^{3} \mathrm{ha}^{-1}$. Entretanto, GOMES FILHO et al. (2001) constataram baixa mobilidade do cobre no solo, afirmando que esse elemento é, entre os metais pesados, um dos mais fortemente adsorvidos pelo solo.

BARROS et al. (2003) afirmaram que, nos processos de infiltração e percolação, o cobre é retido pela maioria dos solos, principalmente quando ricos em matéria orgânica e com $\mathrm{pH}$ maior que 7, ou ainda por óxidos de ferro, alumínio e manganês, e pelos minerais da argila. Dessa forma, mesmo com a aplicação de ARS favorecendo o aumento da matéria orgânica e da CTC no solo e, consequentemente, maior retenção de cátions, ocorreu diminuição do cátion $\mathrm{Cu}^{2+}$ de cobre no solo, que pode estar associado com pontos já relacionados, uma vez que não foram observadas grandes perdas por lixiviação do elemento (Tabela 7). 
Para SODRÉ et al. (2001), ambientes ácidos determinam maior mobilidade dos metais no solo, enquanto condições de $\mathrm{pH}$ acima de seis favorecem a sua retenção. OLIVEIRA \& MATTIAZZO (2001) complementaram afirmando que a maior ou a menor mobilidade dos metais pesados será determinada pelos atributos do solo, como teores e tipos de argila, $\mathrm{pH}$, capacidade de troca de cátions, teor de matéria orgânica, entre outros, que influenciarão nas reações de adsorção/dessorção, precipitação/dissolução, complexação e oxirredução. Neste sentido, BARROS et al. (2003) aplicaram água residuária em três solos arenosos, argilosos e de textura média, e observaram que os solos argilosos, como é o caso do presente estudo, retêm maiores concentrações de cobre e de zinco no solo, diminuindo seu potencial poluente para o lençol freático.

A ausência de diferenças significativas para o cobre, entre as taxas de ARS, verificada no estudo, pode estar associada à baixa quantidade do elemento presente na ARS utilizada em comparação com demais ARS (Tabela 2), uma vez que o cobre e o zinco presentes nos resíduos dependem do sistema de criação de suínos (BASSO et al., 2005).

SILVA \& MENDONÇA (2007) afirmaram que, dentre os metais pesados, o cobre é um dos menos móveis no solo devido a sua forte adsorção nos coloides orgânicos e inorgânicos do solo. Na matéria orgânica, o cobre é retido principalmente pelos ácidos húmicos e flúvicos, formando complexos estáveis. GIROTTO (2007), após sete anos de aplicação de ARS, observou aumentos dos teores de $\mathrm{Cu}$ e de $\mathrm{Zn}$ no solo e movimentação desses em seu perfil.

$\mathrm{Na}$ Tabela 6, são apresentadas as médias da concentração do zinco no solo sob tratamento com ARS e adubação durante o desenvolvimento do ciclo da cultura da soja. Verifica-se, pela Tabela 6, que as concentrações de zinco no solo variaram em função da aplicação das taxas de ARS, indicando que, com a adição de ARS, o zinco no solo proporcionou concentrações maiores. Observa-se que, aos 59 DAS, o maior teor de zinco foi obtido para a taxa de $300 \mathrm{~m}^{3} \mathrm{ha}^{-1}$ e que diferiu significativamente das demais taxas, que foram semelhantes entre si, significativamente. No período de 118 DAS, nota-se que o tratamento que não recebeu ARS obteve a menor concentração de zinco no solo, a qual foi semelhante ao nível de 5\% das taxas de 100 e $200 \mathrm{~m}^{3} \mathrm{ha}^{-1}$ e diferente da taxa de $300 \mathrm{~m}^{3} \mathrm{ha}^{-1}$; e esta, por sua vez, foi semelhante, significativamente, apenas à taxa de $200 \mathrm{~m}^{3} \mathrm{ha}^{-1}$.

TABELA 6. Resultado do teste de comparação de médias para zinco $\left(\mathrm{mg} \mathrm{dm}^{-3}\right)$ no solo em função dos tratamentos com água residuária de suinocultura, nos períodos de 59 e 118 dias após a semeadura. Results of the mean test comparison for zinc $\left(\mathrm{mg} \mathrm{dm}^{-3}\right)$ on soil in function of the treatment of swine wastewater in the periods of 59 and 118 days after sewing.

\begin{tabular}{ccc}
\hline & \multicolumn{2}{c}{ DAS } \\
\hline Taxas $\left(\mathrm{m}^{3} \mathrm{ha}^{-1}\right)$ & 59 & 118 \\
\hline 0 & $0,60 \mathrm{~A}$ & $0,48 \mathrm{~A}$ \\
100 & $1,10 \mathrm{~A}$ & $1,03 \mathrm{~A}$ \\
200 & $1,17 \mathrm{~A}$ & $1,73 \mathrm{AB}$ \\
300 & $2,70 \mathrm{~B}$ & $2,57 \mathrm{~B}$ \\
\hline
\end{tabular}

As médias apresentadas são obtidas das observações originais, seguidas das letras obtidas na comparação de médias com a transformação $\sqrt{x}$. Letras maiúsculas iguais na coluna não diferem entre si, de acordo com o teste de Tukey, a 5\% de significância. DAS - dias após a semeadura.

Comportamento semelhante foi observado por BERTOL (2005) que, com a aplicação de $60 \mathrm{~m}^{3} \mathrm{ha}^{-1}$ de ARS, verificou concentração de zinco 26 vezes maior em relação à parcela-testemunha e à adubação química. FREITAS et al. (2005) também verificaram incrementos na concentração de zinco no solo com a aplicação de água residuária de suinocultura. $\mathrm{O}$ autor aplicou água residuária bruta e peneirada, e verificou concentrações de 16,3 e $13,1 \mathrm{mg} \mathrm{dm}^{-3}$, respectivamente, no perfil de 0 a $0,5 \mathrm{~m}$, sendo que, na testemunha, a concentração obtida de zinco foi de $0,44 \mathrm{mg} \mathrm{dm}^{-3}$. 
OLIVEIRA (2002) observou que, com a aplicação de doses do composto de lixo, os teores totais de zinco no solo aumentaram linearmente, até a camada de 0,2-0,4 $\mathrm{m}$, no primeiro ano de aplicação, e no segundo ano, os autores observaram que o aumento se deu até 0,4-0,6 m, evidenciando progressão dos teores em profundidade, com as aplicações sucessivas do composto de lixo. No entanto, KONZEN \& ALVARENGA (2005) e QUEIROZ et al. (2004) verificaram que o zinco aplicado via ARS se acumulou mais na superfície do solo $(0-0,2 \mathrm{~m})$. Cabe ressaltar que a concentração de zinco no solo do presente estudo se refere ao perfil de 0-0,6 m. Assim, a lixiviação do elemento pode ser observada apenas por meio do material percolado dos lisímetros. Conforme RAIJ et al. (2001), os teores de zinco no solo foram considerados como baixos $\left(0,0-0,5 \mathrm{mg} \mathrm{dm}^{-3}\right)$, médios $\left(0,6-1,2 \mathrm{mg} \mathrm{dm}^{-3}\right)$ e altos $\left(>1,2 \mathrm{mg} \mathrm{dm}^{-3}\right)$.

PAGANINI et al. (2004) afirmaram que grande quantidade de zinco pode ser fixada na fração orgânica do solo, podendo também ser temporariamente imobilizado nos microrganismos quando se adiciona matéria orgânica ao solo, e por outro lado, grande parte do zinco disponível em um solo mineral está associado com a matéria orgânica. Baixos níveis de matéria orgânica em solos minerais são, frequentemente, indicativos de baixa disponibilidade de zinco. PIERANGELI et al. (2004) complementaram que os elementos na matriz do solo, como óxidos de ferro e alumínio, matéria orgânica e fósforo, são capazes de reter fortemente os metais pesados, como o $\mathrm{Cu}$ e o $\mathrm{Zn}$, uma vez que estão relacionados à maior carga líquida negativa presente nas camadas superiores do solo.

Na Tabela 7, é apresentado o resumo da análise de variância da concentração de cobre no material percolado, em função dos tratamentos com ARS e adubação durante o desenvolvimento da cultura da soja. Observa-se que, para o cobre, o valor de F não foi significativo para nenhum dos fatores avaliados durante o desenvolvimento da cultura da soja. Ressalta-se que não foram observadas concentrações de cobre no material percolado dos lisímetros, aos 114 DAS. O zinco no solo também não apresentou significância para nenhum dos fatores avaliados em todos os períodos analisados.

Embora não tenham sido observadas diferenças estatísticas entre os tratamentos avaliados para nenhum parâmetro, nota-se que a maior concentração de cobre no lixiviado foi verificada nas primeiras coletas (Tabela 7), diminuindo durante o desenvolvimento da cultura. A lixiviação de cobre observada é indício de transferência desse elemento por fluxo preferencial no perfil do solo. Isso pode ser justificado pela alta afinidade desse elemento por compostos orgânicos solúveis em solução (ASHWORTH \& ALLOWAY, 2007). Dessa forma, o $\mathrm{Cu}$ transferido não interage com os coloides de solo porque normalmente, o $\mathrm{Cu}$ é transferido via macroporos que possuem uma proteção em suas paredes, dificultando, assim a interação entre a solução e as partículas de solo. Contudo, de acordo com ANDERSEN et al. (2002), a constante de estabilidade do complexo formado é maior para $\mathrm{Cu}$ em relação ao $\mathrm{Zn}$, por isso a mobilidade do $\mathrm{Cu}$ seria mais influenciada pela presença de substâncias húmicas em suspensão.

Com relação ao zinco no percolado (Tabela 7), nota-se, pela média geral, que aos 58 DAS, foi verificada a maior concentração, o que provavelmente pode estar associado à maior lâmina aplicada na irrigação, o que pode ter provocado maior lixiviação de zinco no período. De acordo com OLIVEIRA \& MATTIAZZO (2001), em condições de pouca ou nenhuma acidez e elevados teores de matéria orgânica, a presença do zinco em solução e de outras formas facilmente lixiviáveis é bastante reduzida. Nessas condições, o metal pode ser facilmente coprecipitado junto aos óxidos de ferro e de alumínio e formar complexos pouco solúveis com a matéria orgânica ou serem fortemente retidos por processos de adsorção específica.

As concentrações de cobre e de zinco obtidas são inferiores às obtidas por BARROS et al. (2003), exceto para as concentrações de cobre nas duas primeiras coletas (Tabela 7). Os autores verificaram que, com aplicação de água residuária de suinocultura após a utilização de tratamento integrado, em colunas deformadas de solo, as concentrações máximas observadas nas soluções percoladas de zinco foram próximas a $0,35 \mathrm{mg} \mathrm{L}^{-1}$ e de cobre próxima a $0,06 \mathrm{mg} \mathrm{L}^{-1}$, o que se assemelha ao obtido no presente estudo. Estes autores citam ainda que, dos solos estudados, o 
argiloso foi o que apresentou maior capacidade de adsorção de cobre e de zinco, fazendo o comparativo com solos de textura média e arenosa, no tratamento integrado, diminuindo o potencial poluente das águas residuárias de suinocultura.

TABELA 7. Resumo da análise de variância para a obtenção dos valores de $\mathrm{F}$ da concentração cobre e zinco $\left(\mathrm{mg} \mathrm{L}^{-1}\right)$ para o material percolado dos lisímetros sob tratamento com água residuária de suinocultura e adubação durante o desenvolvimento da cultura da soja. Summary of variance analysis to obtain the values of $F$ concentration of copper and zinc $\left(\mathrm{mg} \mathrm{L}^{-1}\right)$ for the material of the lysimeters on leachate treatment of swine wastewater and fertilizing during the development of soybean.

\begin{tabular}{|c|c|c|c|c|c|c|}
\hline \multicolumn{7}{|c|}{ Cobre } \\
\hline \multirow{2}{*}{$\begin{array}{l}\text { Fonte de } \\
\text { Variação }\end{array}$} & \multicolumn{6}{|c|}{$\mathrm{F}$} \\
\hline & 44 DAS & $58 \mathrm{DAS}$ & \multicolumn{2}{|c|}{72 DAS } & 86 DAS & 100 DAS \\
\hline$\overline{\mathrm{ARS}}$ & $1,30^{\mathrm{ns}}$ & $0,86^{\mathrm{ns}}$ & \multicolumn{2}{|c|}{$2,30^{\mathrm{ns}}$} & $2,06^{\mathrm{ns}}$ & $0,86^{\mathrm{ns}}$ \\
\hline $\mathrm{AD}$ & $0,09^{\mathrm{ns}}$ & $0,61^{\mathrm{ns}}$ & \multicolumn{2}{|c|}{$1,24^{\mathrm{ns}}$} & $3,08^{\mathrm{ns}}$ & $0,28^{\mathrm{ns}}$ \\
\hline ARS $x$ AD & $1,36^{\mathrm{ns}}$ & $0,93^{\mathrm{ns}}$ & \multicolumn{2}{|c|}{$1,52^{\mathrm{ns}}$} & $1,68^{\mathrm{ns}}$ & $1,19^{\mathrm{ns}}$ \\
\hline Bloco & $44,40^{*}$ & $3,10^{*}$ & \multicolumn{2}{|c|}{$2,10^{\mathrm{ns}}$} & $14,99^{*}$ & $5,44^{*}$ \\
\hline C.V. (\%) & 6,45 & 8,12 & \multicolumn{2}{|c|}{1,07} & 1,88 & 1,13 \\
\hline Média geral & 0,26 & 0,11 & & & 0,03 & 0,02 \\
\hline \multicolumn{7}{|l|}{ 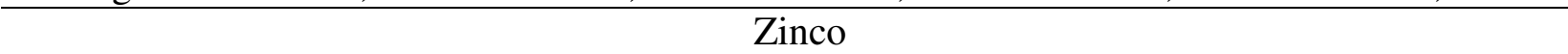 } \\
\hline \multirow{2}{*}{$\begin{array}{l}\text { Fonte de } \\
\text { Variação }\end{array}$} & \multicolumn{6}{|c|}{$\mathrm{F}$} \\
\hline & 44 DAS & 58 DAS & $72 \mathrm{DAS}$ & 86 DAS & 100 DAS & 114 DAS \\
\hline$\overline{\mathrm{ARS}}$ & $1,82^{\mathrm{ns}}$ & $1,45^{\mathrm{ns}}$ & $2,82^{\mathrm{ns}}$ & $0,58^{\mathrm{ns}}$ & $0,06^{\mathrm{ns}}$ & $0,29^{\mathrm{ns}}$ \\
\hline $\mathrm{AD}$ & $0,07^{\mathrm{ns}}$ & $0,66^{\mathrm{ns}}$ & $2,40^{\mathrm{ns}}$ & $0,00^{\mathrm{ns}}$ & $1,29^{\mathrm{ns}}$ & $2,09^{\mathrm{ns}}$ \\
\hline ARS $x$ AD & $2,94^{\mathrm{ns}}$ & $1,30^{\mathrm{ns}}$ & $1,69^{\mathrm{ns}}$ & $0,85^{\mathrm{ns}}$ & $0,70^{\mathrm{ns}}$ & $0,97^{\mathrm{ns}}$ \\
\hline Bloco & $20,68^{*}$ & $2,66^{\mathrm{ns}}$ & $1,44^{\mathrm{ns}}$ & $0,15^{\mathrm{ns}}$ & $0,02^{\mathrm{ns}}$ & $2,76^{\mathrm{ns}}$ \\
\hline C.V. (\%) & 37,19 & 13,77 & 22,67 & 38,08 & 24,07 & 14,76 \\
\hline Média geral & 0,01 & 0,05 & 0,02 & 0,02 & 0,02 & 0,02 \\
\hline
\end{tabular}

Considerando que os limites máximos de cobre e de zinco em rios da classe 1 e 2 (águas doces) é de $0,009 \mathrm{mg} \mathrm{L}^{-1}$ e $0,18 \mathrm{mg} \mathrm{L}^{-1}$, respectivamente, conforme a Resolução 357/2005 do CONAMA (BRASIL, 2005), nota-se que, em todos os períodos avaliados, as concentrações médias de cobre ficaram acima do estabelecido, e as do zinco foram abaixo do padrão. Entretanto, se se considerar o limite de cobre e de zinco no lançamento de efluentes em corpos d'água, de acordo com a resolução, observa-se que todas as concentrações de cobre e de zinco verificadas ficaram abaixo do estabelecido de $1,0 \mathrm{mg} \mathrm{L}^{-1}$ (cobre dissolvido) e 5,0 $\mathrm{mg} \mathrm{L}^{-1}$, respectivamente.

Diante das concentrações obtidas de cobre e de zinco no material percolado e verificando os teores de cobre e de zinco no solo (Tabelas 6 e 7), nota-se que o solo obteve capacidade de reter os metais, evidenciando, portanto, efeito depurador importante no período avaliado.

\section{CONCLUSÕES}

Nas condições em que foi realizado este estudo, é possível concluir que o cobre presente no solo não apresentou diferenças com a aplicação de ARS e adubação, enquanto as concentrações de zinco no solo foram influenciadas pelas taxas aplicadas de ARS, sendo as maiores concentrações verificadas nas maiores taxas de 200 e $300 \mathrm{~m}^{3} \mathrm{ha}^{-1}$. As concentrações de zinco no solo aumentaram 
com a aplicação de ARS ao longo do tempo. As transferências de cobre e de zinco por percolação foram pouco expressivas.

\section{REFERÊNCIAS}

ANDERSEN, M.K.; REFSGAARD, A.; RAULUND-RASMUSSEN, K.; STROBEL, B.W.; HANSEN, H.C.B. Content, distribution, and solubility of cadmium in arable and forest soils. Soil Science Society of America Journal, Madison, v.66, n.6, p.1.829-1.835, 2002.

APHA, AWWA, WEF. Standard methods for the examination of water and wastewater. 20th ed. Washington: American Public Health Association, 1998. 1.193 p.

ASHWORTH, D.J.; ALLOWAY, B.J. Complexation of copper by sewage sludge-derived dissolved organic matter: effects on soil sorption behaviour and plant uptake. Water Air Soil Pollution, Dordrecht, v.182, n.1, p.187-196, 2007.

ASSMANN, A.P.; SANTOS, I. dos; ASSMANN, J.M.; BRAIDA, J.A.; MALAGI, G. Efeito de doses crescentes de esterco líquido de suínos na intensidade de antracnose e produtividade de soja. Synergismus scyentifica UTFPR, Pato Branco, v.1, n.1-4, p.1-778, 2006.

BARROS, L.S.S.; AMARAL, L.A. do; LUCAS JÚNIOR, J. de. Poder poluente de águas residuárias de suinocultura após utilização de um tratamento integrado. Brazilian Journal of Veterinary Research And Animal Science, SãoPaulo, v.40, n.2, p.126-135, 2003.

BASSO, C.J.; CERETTA, C.A.; DURIGON, R.; POLETTO, N.; GIROTTO, E. Dejeto líquido de suínos: II - perdas de nitrogênio e fósforo por percolação no solo sob plantio direto. Ciência Rural, Santa Maria, v.35, n.6, p.1.296-1.304, 2005.

BERTOL, O.J. Contaminação da água de escoamento superficial e da água perolada pelo efeito de adubação mineral e adubação orgânica em sistema de semeadura direta. 2005. $209 \mathrm{f}$. Tese (Doutorado em Engenharia Florestal) - Universidade Federal do Paraná, Curitiba, 2005.

BRASIL. Ministério do Meio Ambiente. Conselho Nacional do Meio Ambiente. Resolução no 357 de 17 de março de 2005. Diário oficial da União, Brasília, DF, 18 mar. 2005.

CERETTA, C.A.; BASSO, C.J.; VIEIRA, F.C.B.; HERBES, M.G.; MOREIRA, I.C.L.; BERWANGER, A.L. Dejeto líquido de suínos: I - perdas de nitrogênio e fósforo na solução escoada na superfície do solo, sob plantio direto. Ciência Rural, Santa Maria, v.35, n.6, p.1.2961.304, 2005.

CERETTA, C.A.; DURIGON, R.; BASSO, C.J.; BARCELLOS, L.A.R.; VIEIRA, F.C.B. Características químicas do solo sob aplicação de esterco líquido de suínos em pastagem natural. Pesquisa Agropecuária Brasileira, Brasília, v.38, n.6, p.729-735, 2003.

DAL BOSCO, T.C. Poluição difusa decorrente da aplicação de água residuária da suinocultura em solo cultivado com soja sob condições de chuva simulada. 2007. 128 f. Dissertação (Mestrado em Recursos Hídricos e Saneamento Ambiental) - Universidade Estadual do Oeste do Paraná, Cascavel, 2007.

FREITAS, W.S.; OLIVEIRA, R.A.; CECON, P.R.; PINTO, F.A.; GALVÃO, J.C.C. Efeito da aplicação de águas residuárias de suinocultura em solo cultivado com milho. Engenharia na Agricultura, Viçosa, v.13, n.2, p.95-102, 2005.

GIROTTO, E. Cobre e zinco no solo sob uso intensivo de dejeto líquido de suínos. 2007. $121 \mathrm{f}$. Dissertação (Mestrado em Ciência do Solo) - Universidade Federal de Santa Maria, Santa Maria, 2007.

GOMES FILHO, R.R.; MATOS, A.T.; SILVA, D.D.; MARTINEZ, H.E.P. Remoção de carga orgânica e produtividade da aveia forrageira em cultivo hidropônico com águas residuárias da 
suinocultura. Revista Brasileira de Engenharia Agrícola e Ambiental, Campina Grande, v.5, n.1, p.131-134, 2001.

GRÄBER, I.; HANSEN, J.F.; OLESEN, S.E.; HANS, J.P.; OSTERGAARD, H.S.; KROGH, L. Accumulation of copper and zinc in danish agricultural soils in intensive pig production areas. Danish Journal of Geography, Copenhagen, v.105, n.2, p.15-22, 2005.

HUE, N.V.; LICUDINE, D.L. Amelioration of subsoil acidity through surface application of organic manures. Journal Environmental Quality, Madison, v.28, n.2, p.623-632, 1999.

HSU, J.H.; LO, S.L. Effect of composting on characterization and leaching of copper, manganese, and zinc from swine manure. Environmental Pollution, Boston, v.114, n.1, p.119-127, 2000.

JONDREVILLE, C.; REVY, P.S.; DOURMAD, J.Y. Dietary means to better control the environmental impact of copper and zinc by pigs from weaning to slaughter. Livestock Production Science, New York, v.84, n.2, p.147-156, 2003.

KONZEN, E.A.; ALVARENGA, R.A. Manejo e utilização de dejetos animais: aspectos agronômicos e ambientais. Sete Lagoas: EMBRAPA/CNPMS, 2005. (Circular Técnica, 63)

LONGO, A.J.; SAMPAIO, S.C.; SUSZEK, M. Equação de chuvas intensas e precipitação provável para o município de Cascavel-PR. Varia Scientia, Cascavel, v.6, n.12, p.16-30, 2006.

MALAVOLTA, E.; PIMENTEL GOMES, F.; ALCARDE, J.C. Adubos e adubações. São Paulo: Nobel, 2002. 199 p.

MATOS, A.T.; SEDIYAMA, M.A.N.; FREITAS, S.P.; VIDIGAL, S.M.; GARCIA, N.C.P.

Características químicas e microbiológicas do solo influenciadas pela aplicação de dejeto líquido de suínos. Revista Ceres, Viçosa, MG, v.44, n.254, p.399-410, 1997.

MATTIAS, J.L. Metais pesados em solos sob aplicação de dejetos líquidos de suínos em duas microbacias hidrográficas de Santa Catarina. 2006. 165 f. Tese (Doutorado em Ciência do Solo) Universidade Federal de Santa Maria, Santa Maria, 2006.

OLIVEIRA, F.C.; MATTIAZZO, M.E. Mobilidade de metais pesados em um Latossolo Amarelo distrófico tratado com lodo de esgoto e cultivado com cana-de-açúcar. Scientia Agrícola, Piracicaba, v.58, n.4, p.807-812, 2001.

OLIVEIRA, P.A.V. Curso de capacitação em práticas ambientais sustentáveis: treinamentos 2002. Concórdia: Embrapa Suínos e Aves, 2002. 112 p.

PAGANINI, W.S. da; SOUZA, A. de; BOCCHIGLIERI, M.M. Avaliação do comportamento de metais pesados no tratamento de esgotos por disposição no solo. Engenharia Sanitária e Ambiental, Rio de Janeiro, v.9, n.3, p.225-239, 2004.

PEREIRA, E. Qualidade da água residuária em sistemas de produção e de tratamento de efluentes de suínos e seu reúso no ambiente agrícola. 2006. 129 f. Tese (Doutorado em Irrigação e Drenagem) - Universidade de São Paulo, Escola Superior de Agricultura "Luiz de Queiroz", Piracicaba, 2006.

PIERANGELI, M.A.P.; GUILHERME, L.R.G.; CURI, N.; ANDERSON, S.J.; LIMA, J.M. Adsorção e dessorção de cádmio, cobre e chumbo por amostras de Latossolos pré-tratadas com fósforo. Revista Brasileira de Ciência do Solo, Viçosa - MG, v.28, n.2, p.377-384, 2004.

PIMENTEL GOMES, F. Curso de estatística experimental. 14.ed. Piracicaba: Degaspari, 2000. $477 \mathrm{p}$.

QUEIROZ, F.M.; MATOS, A.T.; PEREIRA, O.G.; OLIVEIRA, R.A. Características químicas de solo submetido ao tratamento com esterco líquido de suínos e cultivado com gramíneas forrageiras. Ciência Rural, Santa Maria, v.34, n.5, p.1.487-1.492, 2004. 
RAIJ, B.V.; ANDRADE, J.C.; CANTARELLA, H.; QUAGGIO, J.A. Análise química para avaliação da fertilidade de solos tropicais. Campinas: Instituto Agronômico, 2001. 285 p.

SCHERER, E.E.; CASTILHOS, E.G.; JUCKSCH, I.; NADAL. R. Efeito da adubação com esterco de suínos, nitrogênio e fósforo em milho. Florianópolis: EMPASC, 1984. 26 p. (Boletim Técnico, 24)

SILVA, I.R.; SÁ MENDONÇA, E. Matéria orgânica do solo. In: NOVAIS, R.F.; ALVAREZ, V.H.; FONTES, R.L.F.; CANTARUTI, R.B.; NEVES, J.C.L. (Ed.). Fertilidade do solo. Viçosa-MG: Sociedade Brasileira de Ciência do Solo, 2007. p.275-374.

SODRÉ, F.F.; LENZI, E.; COSTA, A.C. Utilização de modelos físico-químicos de adsorção no estudo do comportamento do cobre em solos argilosos. Química Nova, São Paulo, v.24, n.3, p.324330, 2001.

SPERLING, E. Von. Qualidade da água. In: SILVA, D.D. da; PRUSKI, F.F. Recursos hídricos e desenvolvimento sustentável da agricultura. Brasília: UFV, 1997. p.89-114. 